\title{
Brief Analysis on the Promoting Function of Private Education in Urbanization Process
}

\author{
Hua Peng \\ Huanghe Science and Technology College \\ Zhengzhou, China
}

\begin{abstract}
After the reform and opening up, our country accelerates turning from traditional agricultural society to modern industrial society. Urbanization process is one of the typical symbols of the progress of this profound social form and it is endowed with the "strategic role of expanding domestic demand" by many scholars. In urbanization process, the advantages of private education mainly reflect in aspects that it has important position in the whole education system of our country and flexible school-running mechanism, and efficiently provides large-scale high-skilled talents for the urbanization process in our country.
\end{abstract}

Keywords-urbanization; private education; resource allocation

\section{INTRODUCTION}

As an important part of educational career in our country, private education is supposed to actively play a positive role in national and local major strategic decision-makings. With the acceleration of urbanization construction in our province, discussing the position and role of private education in the urbanization process of our province helps government and private education industry to correctly position their role and development direction in the new period, optimize the allocation ratio of resources of private education at all levels, fully grasp the development opportunities brought by national policy and provide better educational resources for our society.

\section{RESEARCH ON LEADING ROLE OF EDUCATION IN URBANIZATION PROCESS}

Carefully studying on practical experience and relevant research achievements of urbanization of our country as well as developed countries in the world, we can find that the investment level of regional education always has close relationship of positive correlation with the quality of urbanization. Generally speaking, the higher level of the per capita fiscal expenditure on education is, the higher the urbanization level will be. From this perspective, education has obvious leading role in urbanization. Since the Meiji restoration, the social economy in Japan that has scanty natural resources has developed rapidly. The industrialization drives the rapid rising of urbanization rate. Thereby, Japan, the island country in East Asia, walks on the

This paper is one of the periodical achievements of Prospective Study on Educational Resources Distribution in the Process of Urbanization (2015-JSJYZD-080) as the key project of "Research on Henan Provincial Teacher Education Curriculum Reform in 2015". road of enriching the country and increasing its military force. Many research results indicate that the rising of Japan cannot do without the substantial support of Meiji government for modern education. As early as 1882, Japanese government began to implement mandatory elementary school compulsory education. Meiji government invested an enormous sum of money in school education. Data shows that the appropriation expenditure of Japanese Ministry of Education that takes charge of education occupies the first place in all departments. The proportion of education spending keeps about ten percent in national and local administrative costs. Besides, the government encouraged the national to actively support education. Finally, it made the educational reform in Japan achieve success at that time, which greatly promoted the industrialization and urbanization process. According to estimates of experts, if the population proportion of university degree or equivalent increases one percent, it can drive the urbanization rate to accordingly increase 0.40 percent; if the population proportion of high school degree increases one percent, the urbanization rate will increase 0.16 percent. [3] After Chinese Academy of Social Sciences does research on associated data of urbanization in 2010 of 286 prefecture-level city in our country, the results show that among the top ten cities with relatively high per capita fiscal expenditure on education in our country, the quality index number of urbanization of seven cities is in top ten; among the bottom ten cities with relatively low per capita fiscal expenditure on education, the quality index number of urbanization of six cities is after the top 200. [4] From the lengthways perspective, the several decades with rapid development of urbanization in our country are just the period when the education at all levels develops rapidly. In this process, we have popularized the nine-year compulsory education and realized the popularization of higher education. Relevant historical materials prove our opinion: In 1979, the educational fund input in our country was only about 10.4 billion yuan; by 2012, the educational fund expenditure in our country reached about 2,000 billion yuan. The proportion that it accounts for in gross domestic product in that year increased to four percent; the development level of urbanization can also conformed to it. In 1979, the urbanization rate in our country was less than 19 percent; while in 2012, the urbanization rate of conservative estimate reached 42 percent. Therefore, a lot of related researches transform the development situation of regional education 
into positive index to examine and weigh the quality of urbanization.

The promotion of educational level can enhance production efficiency and guarantee that the agricultural population of transfer can continuously receive higher quality of education in knowledge and skills in the process of moving toward citizenship. Therefore, increasing educational input for agricultural population of transfer is also regarded as the effective way to accelerate urbanization. We must fully realize that urbanization cannot simply transfer and gather agricultural people to the city. It is an important opportunity for the transformation and upgrading of industrial structure in our country as well as the scientific measure to steadily boost surplus rural labor force to transfer to the secondary and tertiary industries. In some countries, because the governments do not pay attention to improving the degree of education of farmers in urbanization, many farmers not only lose their lands in the countryside, but also lack the skills to make a living in cities. They gather in the edge zone of the city. A large number of "slums" form gradually. We should fully alert this kind of phenomenon. Because of the long-term existence of urban-rural dual economic structure and serious imbalance of allocation of educational resources, there is a great gap between the development level of educational career in rural area of our country and the level in the city. Most of the high-quality educational resources gather in cities, while farmers who occupy most of the population of China universally cannot receive high-quality general education and vocational training. The phenomenon leads to the fact that after surplus rural labor forces enter cities, they mainly gather in construction site and production lines in factories to work. These posts are unstable and have low additional value of labor, extremely limited development space, and relatively poor environment. They are even regarded as "make a living on the mere strength of their young age" by other people. Therefore, in our opinion, the tide that peasant-workers enter into cities to work cannot be called as urbanization in its true sense. Compared with the primary industry, at present, the secondary and tertiary industries have higher requirements for the culture and skills and qualities of workers. The posts of higher levels also have accordingly higher requirements for knowledge and technique of workers. Therefore, in order to realize the smooth transfer of agricultural labor force, it is essential to continuously improve the cultural quality and occupational skills of workers in our province.

When our country carries out the large-scale urbanization construction, promoting the harmonious development of education at all levels will help to promote the quality of urbanization and it is more beneficial to the sustainable development of urban construction in our country. Through the rapid development in the preceding period of time, the urbanization in our country has made great achievements and accumulated rich construction experience. But in this process, it also accumulates many contradictions that are difficult for us to reconcile. With the boost of urbanization process and the development of economic society, these contradictions lead to the situation that the speed of urbanization in many places doesn't conform to the quality. Under this development trend, we refer to the mature experience of developed countries, put forward and implement the development patterns of new-type urbanization, promote the transformation and upgrade of traditional industries and vigorously promote the structural transformation of cities. The new-type urbanization takes the construction of knowledge-oriented society as the important objective, insists on walking the intensive and high efficient, ecofriendly road, emphasizes using new knowledge and new technology to promote economic and social development, uses smart city to lead the development, uses talent aggregation to promote the urban development, and intensifies the leading role of the market for the allocation of resources with more diversified and powerful motive force of development. Obviously, new-type urbanization has higher requirements for the knowledge level and technical skills of workers. Under this tendency, it is necessary for our country to further strengthen the input and policy support for educational field especially higher education and vocational education, to substantially improve the talent cultivating quality and make the educational level can truly adapt to and drive the development of new-type urbanization.

\section{The Position of PRIVATE EdUCATION MAKES IT} PLAY AN INDISPENS ABLE ROLE IN URBANIZATION PROCESS

\section{A. Private Education Occupies an Unshakable and Important Position in the Whole Education System in Our Country}

In more than 30 years of development of private education in our country, workers in the field of private education overcome many difficulties and dare to explore in order to rapidly expand the overall school-running scale of private education career. The school-running type gradually covers all levels and types of education. The school-running level is improved steadily. It effectively promotes the educational equality, enriches the supply of educational resources and increasingly reflects good social benefits, especially in the field of preschool education. According to the statistical data of the Ministry of Education of our country, among 166,750 institutions of preschool education, there are 115,404 private kindergartens, which account for close to 70 percent; the quantitative proportion of children in the kindergartens is 50 percent. Private education occupies the dominant position in preschool education. Its role in the development of preschool education in our country cannot be ignored. In the field of higher education and vocational education, when private schools develop rapidly, it has provided large number of excellent professionals for the upgrading and transformation of industrial structure in our country and the urbanization construction. Meanwhile, it has made important contributions for the construction of human resources to make our country become strong.

In the urbanization process, the harmonious development of education is essential. As the newly emerging force of the education career in our country, private education becomes bigger and bigger, stronger and stronger and has become an integral part of education system of our country. In 2010, our country issued the National Medium and Long-term Plan for 
Education Reform and Development (2010-2020), which makes it clear that private education is the important growth points of the development of educational career and the important force to promote the educational reform and it is necessary to further strongly support private education. Therefore, it is obvious that with the gradual introduction of a series of encouraging measures in our country, the position of private education will be further steadied and promoted. In the urbanization process, we should not only realize the continuous expansion of educational scale and the sharp rise of the quality of education, but also optimize and adjust the educational structure. Private education will be greatly supported by our country in some fields and even maybe occupy the dominant position in some fields. There are hardwon development opportunities for private education. If private education can fully excavate its potential and closely depend on beneficial external social macro environment, it can consolidate and strengthen its position in the whole industry structure and play a more important role in urbanization process.

\section{B. The School-running System of Private Education Is Flexible and It Can Effectively Make Up for the Deficiency of Public Education}

In the preliminary period of private education career in our country, depending on its unique flexibility, private education can rapidly seek a breakthrough in the national education pattern that public education occupied the dominant position at that time, and then develop and grow. Meanwhile, this kind of development also effectively makes up for the deficiency of public education in the aspect of structure and layout and make the education system of our country become more perfect and healthy. At the present stage, the flexibility of private education system still has important significance on coordinating the balanced development between urbanization and education. Especially under the condition that the urbanization process can provide bigger development opportunity and space for private education, the advantage in system is easier to be stimulated and become the vitality of school running.

First of all, with the steady development of urbanization in our country, the long-standing urban-rural dual economic structure in our country will be broke thoroughly. The enormous gap between the country and the city will be eliminated. This tendency will gradually strengthen the attraction of the country and small towns, and prompt highquality educational resources to flow to small towns to make the educational resources become increasingly balanced. Compared with public education, private education has relatively strong autonomous right, flexible school-running system; has sensitive reaction to policies. It is easy for private education to seize the first opportunity and take the lead in making overall arrangement in the burgeoning education career in cities and towns. Secondly, private education has rich and diversified school-running forms and is good at designing teaching model with strong pertinence. They have passed the long-term practical test in the field of professional education such as training of special skills and language training, accumulated rich school-running experience and have relatively mature school-running pattern In the urbanization process, the income of people will be certainly increased integrally and sharply. The masses will have increasingly strong willing to receive education and they will have diversified requirements for the types of education. The above characteristics of private education can provide richer more diversified educational resources for the masses. Finally, because the obstacles formed by household registration system still exist, there are still many difficulties for preschool education and public education in the elementary education stage to accept the entrance of agricultural population of transfer. Benefited by the policy of our country, private education will not be influenced by this kind of factor. It can meet the actual demands of these people and make up for the deficiencies of public education. According to the above advantages, we can make sure that there is still huge development space for private education in urbanization process.

\section{Private Secondary Vocational Education and Higher Education Can Effectively Provide Large-Scale High- Skilled Talents for the Urbanization Process in Our Country}

In view of the strong leading role of education in urbanization, the urbanization process of various countries in the world are all accompanied with the great-leap-forward development of education at all levels. However, because education sector is recognized as the public welfare industry and the services provided by it have the characteristics of public products; and because the social capital has the nature of profit-seeking, the development and progress of education also mainly depend on the continuous investment of national finance. In order to meet the requirements of economic and social development for talents and improve the levels of knowledge and skills of workers, the National Medium and Long-term Plan for Education Reform and Development (2010-2020) puts forward that by 2020, our country will popularize high school and secondary vocational education, further improve the level of popularization of higher education and increase the average years of education of incoming labor force to 13.5 years. However, when the implementation of these educational policies provides large number of high-skilled labor force for the urbanization in our country, it will inevitably and continuously produce high pressure on national and local public finance. Under this background, it is very necessary and urgent for the whole education industry of our country to expedite the establishment of the flexible allocation model of educational resources, effectively increase the usage efficiency of educational funds and greatly enrich the channels of sources of educational capital. In 2006, the Ministry of Education in our country issued the Opinions on the Development of Private Secondary Vocational Education, which makes it clear that the private secondary vocational education has "cultivated a group of practical talents who can meet the requirements of economic and social development" and demands that "greatly develop private secondary vocational education as well as public secondary vocation education", in order to meet the urgent demands of economic and social development for high-quality workers and skilled talents 
who work in the frontline of production and service. The clear support of our country for private education indicates that it has characteristics and advantages in cultivating talents for economic and social construction; together with public education, it can serve the urbanization construction in our province.

Private education can effectively cultivate large number of talents for the national and provincial urbanization construction. It is mainly embodied in the following aspects: Firstly, private education uses fund raising in the society as the main channel to raise the main school-running funds; meanwhile, it can enjoy the priority of national policy or direct financial subsidies. From another perspective, this is equivalent to the situation that the government uses a small part of financial funds to open the overall situation of the whole private education industry, and then greatly improve the capital usage efficiency of national expenditure on education; Secondly, the talent cultivation mode of private schools must constantly meet the actual requirements of social industry to win the space for further survival and development. Therefore, every private school pays great attention to the positioning of cultivation goals in the schoolrunning process. At the present stage, the positioning of domestic private secondary vocational schools and institutions of higher learning mainly takes the cultivation of skilled and applied talents as the main objective. It conforms to the actual demands of urbanization process of our country for skilled labor force. Therefore, promoting the development of private secondary vocational education and higher education can make the local area effectively reduce the cost of talent training as well as greatly improve the scope and quality of cultivation.

\section{REFERENCES}

[1] Zhang Ran. The Real Urbanization Rate in China is Overestimated by Ten Percent [N], Beijing Times, 2013-7-31

[2] The P.R.C Law for Promoting Private School

[3] Research Group of National School of Development of Beijing University, Research on the Influences of Allocation of Educational Resources on Urbanization Process

[4] Urban Development and Environment Research Institute of China Academy of Social Sciences, Report on Quality of Urbanization in China. 